I Universidade do Estado do Rio de Janeiro (Uerj), Instituto de Ciências Sociais, Rio de Janeiro, RJ, Brasil patriciabirman@gmail.com https://orcid.org/o0oo-0003-I I63-2073

Patrícia Birman'

\title{
NARRATIVAS SECULARES E RELIGIOSAS SOBRE A VIOLÊNCIA: AS FRONTEIRAS DO HUMANO NO GOVERNO DOS POBRES
}

\section{INTRODUÇÃO}

Já contamos algumas décadas de acumulação de narrativas sobre o crime e a violência urbana. Embora se possa afirmar que, de modo geral, elas se apresentam e são reconhecidas como atividades relacionadas ao mundo secular, percebe-se que houve um aumento gradativo de discursos religiosos que participam ativamente da sua problematização nas esferas públicas. É do relacionamento variado entre dinâmicas, dispositivos e personagens religiosos e seculares que trataremos aqui. Vamos explorar encontros e confrontos na esfera pública entre algumas práticas seculares que inscrevem o crime e a violência no cotidiano das cidades com os discursos e práticas religiosas que com elas se relacionam. Sugerimos que o tratamento da violência nesses discursos possui como eixo a distinção entre o humano e o não humano, bem como as pequenas nuanças dispostas ocasionalmente em suas fronteiras. Essas se configuram de forma instável e variada tanto em suas versões seculares quanto religiosas, incluindo também os sentidos atribuídos à dor e ao sofrimento. As ideias religiosas de dor e de sacrifício como caminhos de redenção já conduziram tanto à recusa quanto ao consentimento implícito das práticas de tortura, homicídio, crime e violência. Pouco se tematiza sobre essas formas e os sentidos correntes do sofrimento nas elaborações relativas ao tratamento da violência. O repertório de problematizações e de intervenções micropolíticas em torno da violência nos encaminhou para a importância das relações de gênero nesse campo, com des- 
taque para as éticas que hoje estruturam certas condutas, tanto religiosas quanto seculares.

\section{MORTE, SOFRIMENTO E HORIZONTES DE REDENÇÃO}

Comecemos, então, reproduzindo um pequeno trecho que enuncia, em um DVD posto à venda em São Paulo, a comovente e atrativa história do irmão Amorim (Cortes, 20I4: I86):

A história nua e crua da vida de um jovem sem Deus, vivendo como animal, dormindo em cemitérios e comendo restos de comida, nas latas de lixo. Da morte para a vida, uma emocionante história de vida. Irmão Amorim foi condenado a 24 anos de prisão em uma cidade da Patagônia na Argentina. Neste DVD você irá ver cenas marcantes que você jamais esquecerá.

Retirado de um excelente artigo de Mariana Cortes (20I4), o trecho acima busca atrair possíveis compradores para "uma emocionante história de vida" na capa de um DVD disponível no comércio de bens religiosos pentecostais. Em um lugar público, uma espécie de feira de rua na cidade de São Paulo, circulam sujeitos que colocam à venda experiências de vida nas quais o trânsito entre um sofrimento extremo, próximo à morte, e a conversão religiosa, que reinstaura a vida, é narrado como drama pessoal capaz de ressoar amplamente junto ao público religioso e secular, frequentador desse mercado.

Trata-se de um mercado que faz circularem experiências de vida precárias como uma descrição que amplifica seus males, exagera nos efeitos mortíferos de uma vida bestializada e ressalta a vitória exemplar do convertido. Imaginamos que essas narrativas possuem um bom público consumidor, uma vez que se assemelham a muitas outras recorrentes nas Igrejas pentecostais e em espaços midiáticos religiosamente informados. O foco recai sobre o sofrimento extremo: esse é o ápice de uma autobiografia mergulhada nas condições mais duras da pobreza urbana, compreendidas como efeitos provocados pelo demônio e, afinal, religiosamente superados na forma de renascimento moral e social. São narrativas que parecem encerrar um poder de atração para aqueles que se espalham nas muitas igrejas evangélicas, situadas com particular densidade demográfica nas periferias das cidades. Mariana Cortes (2014: I84) aborda uma prática religiosa que descobriu associada a um mercado popular. Descreve um personagem religioso exemplar dos novos tempos evangélicos:

Convertidos às igrejas evangélicas, principalmente em suas variantes pentecostais e neopentecostais, esses sujeitos, marcados em suas trajetórias biográficas pela precariedade social, veem como perspectiva o engajamento na carreira de "pregadores-itinerantes", cuja principal prerrogativa é "dar o testemunho" em igrejas e eventos, narrando episódios dramáticos de sua trajetória biográfica, como experiências com a criminalidade violenta, mendicância, prostituição, homossexualidade, doenças, deficiências. [...] há, nas narrativas de conversão desses "pregadores", o apelo constante para a "estranheza" de suas identidades pregressas, como "ex-mendigos", "ex-bandidos", "ex-assaltantes", "ex-traficantes", 
"ex-deficientes físicos", "ex paraplégicos", "ex-mudos", "ex-bruxos", "ex-macumbeiros", "ex-homossexuais", "ex-travestis", "ex-prostitutas", e uma infinidade de outros "ex-".

Certos usos desse gênero religioso, o testemunho, exprimem formas muito atuais de articular política e religião. Com efeito, as biografias dos "ex", como descreve Mariana Cortes, são também elaboradas mediante pano de fundo calcado em experiências relacionadas à morte de parentes e amigos (na modalidade extermínio) e às muitas faces da precariedade (trabalho, moradia, entre outras) presentes no cotidiano dos pobres urbanos.

Enquanto gênero amplamente difundido em cultos pentecostais, o testemunho não tem limites temáticos precisos. O exemplo que destacamos dos "ex-tudo", os "pregadores itinerantes" descritos por Mariana Cortes, se associa a um horizonte social, político e religioso relativo ao lugar dos pobres nas cidades (cf. Birman, 20I7). O desumano, nas poucas linhas que reproduzimos do testemunho do irmão Amorim, constitui-se como uma narrativa em que se destaca a vida vivida no sofrimento, em uma existência sem amparo, reduzida a uma sociabilidade mínima, posto que teria perdido, também, as formas mais naturalizadas de habitar o próprio corpo: comer, dormir e morar. Atividades que apontam e definem, em sua falta, a desumanidade que o irmão Amorim viveu no passado: "ele comeu lixo, dormiu com os mortos e viveu na prisão".

Esses e outros testemunhos revelam forma de se apropriar das experiências de pobreza urbana por uma específica matriz teológica, que associa o sofrimento à violência e ao crime praticados por aquele que é também uma de suas vítimas. Grosso modo, o horizonte de vida cultivado em algumas igrejas evangélicas projeta a redenção religiosa como um resultado obtido pela graça divina que atuou sobre as dificuldades do fiel nos terrenos da pobreza, da violência, do crime e, em consequência, do sofrimento. $O$ que assim se materializa como religioso e político, no testemunho que citamos, possibilita, no entanto, mais do que a narrativa de uma vitória pessoal, visto que as igrejas e os pregadores articulam, por meio dessa vitória, dois planos que se entrelaçam na esfera pública: salvar os criminosos da morte e a cidade do crime. ${ }^{I}$ Como veremos adiante, o combate secular aos criminosos, ao defini-los como inimigos da cidade, retirou-os de um pertencimento pleno à condição humana. Sob a condição de inimigos é preciso combatê-los. Algumas igrejas pentecostais afirmam que o diabo se encontra encarnado nessa figura da destruição. A guerra secular pôde associar-se à guerra espiritual - instrumentos que vieram a ser cada vez mais claramente propostos para combater a violência. Assim, buscar salvar os inimigos da cidade da morte (quase) certa e de sofrimentos intensos por meio da redenção se estabeleceu como um objetivo partilhado. Os dois caminhos não foram construídos de modo a ser incompatíveis. Ao contrário, são vistos como complementares em suas faces secular e religiosa. 


\section{HORIZONTES MODERNOS EM CAUSA: AS NARRATIVAS SECULARISTAS SOBRE A GUERRA E A TORTURA}

Comecemos pela guerra. Talal Asad (I993, 2003), autor conhecido por seu trabalho renovador nos estudos da religião, dedicou-se mais recentemente ao questionamento crítico das premissas do secularismo, isto é, das narrativas por excelência que historicamente estabeleceram as relações hierarquizadas de sentido entre os polos secular e religioso, sobretudo ao longo da modernidade europeia. Lembremos, pois, com Asad (2003, 20II) que a perspectiva secularista historicamente se estabeleceu no Ocidente como intrínseca ao progresso constitutivo da modernidade. Nessa grande narrativa cujo caráter fundacional é amplamente reconhecido, as forças obscurantistas da tortura, do cadafalso, da exibição de corpos estraçalhados teriam sido derrotadas para dar lugar à racionalidade iluminista e aos princípios civilizatórios, progressivamente consolidados tanto nas mentes quanto nos corpos (Asad, 2003: I00). A narrativa secularista, conforme aponta Hirshkind (20I7), sempre se confundiu com o processo de modernização do mundo a partir do Ocidente. Foi essa perspectiva civilizatória que construiu as colônias, o tratamento de suas populações dentro e fora das metrópoles europeias e justificou a escravidão além-mar.

Acompanhemos então as reflexões de Asad (20I I) no texto em que associa a discussão do secularismo pelo viés dos sentidos modernos atribuídos ao sofrimento, abordando a crueldade e a tortura. Com efeito, o autor enfatiza o modo como a narrativa da modernidade secular fez da produção do sofrimento algo pouco compatível com a civilização: essa teria perdido a legitimidade desfrutada em épocas pregressas. No entanto, como observa,

a história moderna da "tortura" não é somente um registro da progressiva proibição de práticas cruéis, desumanas e degradantes. É também parte de uma narrativa secular de como alguém se torna verdadeiramente humano (Asad, 20II: I74).

E nesse sentido afirma que "durante o processo de aprendizado da humanidade plena (nas sociedades coloniais) somente alguns tipos de sofrimento foram pretensamente eliminados" (Asad, 20I I: I74). O sofrimento desumano, destaca o autor, foi também definido pelo discurso da reforma colonial. Punir os comportamentos considerados bárbaros e moralmente intoleráveis faria parte dessa reforma:

Claramente, então, houve sofrimento e sofrimento no progresso secular [...] não é somente que algumas formas de sofrimento foram tidas como mais sérias do que outras, mas que o sofrimento "desumano", em oposição ao sofrimento "necessário" ou "inevitável", era percebido como essencialmente gratuito e, portanto, punível juridicamente. Por outro lado, a dor suportada ao longo do movimento de se tornar "plenamente humano" era necessária no sentido de que havia razões sociais ou morais pelas quais tinha de ser sofrida (Asad, 20II: I76). 
Talal Asad assinala que em sociedades civilizadas seria de esperar que as práticas militares de infligir dor fossem consideradas, com o passar do tempo, moralmente inaceitáveis. Essa hipótese parece ainda fazer sentido devido à crença no caráter evolutivo e progressivo dos valores associados ao moderno e ao secular. Ele, porém, argumenta, com razão, que a produção da dor que antes chocava agora choca cada vez menos. A relativização da dor e os critérios de aceitabilidade do sofrimento têm nas guerras atuais um exemplo de seus efeitos, a saber, a elaboração cada vez mais sofisticada tecnologicamente de impor novas formas de sofrimento. Gases, bombas com estilhaços, napalm, minas, queimaduras por petróleo nas peles humanas e um arsenal sempre renovado para provocar cada vez mais destruição.

Resumidamente, as cruéis tecnologias modernas de destruição são integrais ao modo moderno de guerrear... Na guerra, o Estado moderno requer de seus cidadãos não apenas que eles matem e mutilem os outros, como também que eles sofram mortes e dores cruéis. A vida humana é sagrada, mas somente em contextos particulares que o Estado define (Asad, 20II: I80).

As reflexões do autor vão no sentido de apontar não somente um amortecimento do que se sente em relação aos atos cruéis, mas também um modo cada vez mais complacente e relativista de encarar esses usos da força bruta quando estão em jogo razões políticas e jurídicas. As doutrinas securitárias correntes, nesse sentido, construíram paulatinamente critérios sobre o uso de medidas cruéis, como a tortura (raramente nomeada como tal) ou medidas extremas (como o extermínio de populações civis), e assim indicam os limites razoáveis para sua aplicação: à medida que se atenham aos objetivos a alcançar, sempre maleáveis, aliás, equilibram-se os benefícios com os efeitos destrutivos também gerados.

Destaquemos nesse mesmo sentido, as formulações de Agamben (2004,) sobre o Estado de exceção, o trabalho de John e Jean Comaroff (20I 2), de Achilles Mbembe (20I6) e de Stephan Graham (20I6), cujas descrições das tecnologias de guerra e da militarização indicam crescente indistinção entre os estados de guerra e de não guerra, da lei e do crime, da ordem e da desordem. Em resumo, estamos diante de um uso constante e cumulativo de formas mortíferas de combate e de vigilância sobre populações civis e um emaranhado reiterado entre atividades de paz e de guerra. ${ }^{2}$ Jogos de guerra virtuais e alvos presenciais efetivos se articulam de tal forma, que parece impossível distinguir espaços de guerra daqueles ditos pacificados. Todos, em suma, submetidos aos circuitos das práticas de combate militarizado e de controle armado da paz.

E, desse ponto de vista, defende Asad (20I I), os atos cruéis podem e são relativizados. Segundo ele, a racionalidade tecnológica permite supor que um uso criminoso da força será reconhecido quando seu emprego não se justificar pelos meios a alcançar - seria excessivo e/ou desnecessário. Pode indicar, por exemplo, um descompromisso com as regras de ataque e defesa que as situações 
exigem. Por outro lado, nessa lógica instrumental da guerra como procedimento corriqueiro e aceitável, não seria legítimo torturar um traficante ou um terrorista para saber onde ele escondeu um jovem sequestrado ou um arsenal de armas? Sabemos que a resposta é sim. Os critérios para o uso da tortura e da morte definitivamente não se atrelam a valores abstratos que supostamente estariam amparados pela modernidade secular.

As práticas de infligir dor e sofrimento são reconhecidas como formas de controle necessárias, ao sabor das circunstâncias. São amparadas na indiferença crescente sobre a morte daqueles que são apontados como inimigos reais, virtuais ou potenciais. As reflexões humanitárias sobre a morte e sobre o sofrimento não parecem pertinentes nos contextos de aplicação dessas lógicas de combate, direcionadas a inimigos internos e externos. Para que fossem legítimas seria preciso retirar suas vítimas dos enquadramentos que as transformaram em alvos desumanizados pela condição de inimigo que lhes foi atribuída. Já a perda de um soldado (tido como integrado à ordem e à civilização) na "guerra ao tráfico", na "guerra ao terrorismo" é legitimamente chorada e dignificada, como podemos acompanhar diariamente na mídia impressa e televisiva. Não tem por que considerar que o uso da violência (como dever militar) ordenado pelo Estado deva ser percebido como atos de indivíduos violentos. São atos que se justificam pela racionalidade e tecnologias próprias ao combate nas guerras urbanas e pela militarização crescente de seus espaços. Criticam-se os exageros, o sofrimento desnecessário, a crueldade como ato individual, como chama atenção Talal Asad (20I I), e, por isso, esses comportamentos seriam injustificáveis em circunstâncias limitadas, das quais se ressalta o caráter não inteiramente humano dos inimigos aos quais se dá combate.

A crítica da narrativa secularista, efetivada por esse autor, insiste, portanto, na associação da modernidade atual com práticas violentas e coloca o cálculo e a mensuração como critérios pragmáticos essenciais para torná-la legítima. Embora não explore os sentidos religiosos da dor, os contrapõe a outras experiências:

Porque [...] para os ascetas, assim como para os sadomasoquistas, a dor não é apenas um meio que pode ser mensurado e pronunciado excessivo ou gratuito com relação a um fim. A dor não é uma ação calculada, mas um engajamento passional (Asad, 20II: I84).

Ao chamar atenção para o surgimento na modernidade de outra relação com o sofrimento, visto essencialmente como parte essencial da fabricação do humano e a sua utilização crescente nas formas políticas de construção do Estado-nação, Talal Asad nos inspira a pensar sobre as relações que essa perspectiva secular da guerra e da produção do sofrimento entretém contemporaneamente com os horizontes religiosos de enfrentá-la. Como essas duas faces da dor se fabricam reciprocamente em cidades como o Rio de Janeiro? Como a violência e a crueldade, que cada vez mais são vistas como instrumentos aceitáveis de 
controle das populações perigosas, se constituem por meio das abordagens religiosas junto aos sujeitos que participam dessas guerras sem fim (Mbembe, 2016).

Voltemos ao Brasil e mais particularmente agora ao Rio de Janeiro. Como já sugeriu Márcia Leite (2000) nos idos dos anos I990, a categoria violência configurou-se paulatinamente como importante instrumento para conectar e abranger as muitas atividades e os discursos que participam dos dispositivos relacionados à gestão da guerra, claramente em continuidade com a gestão da pobreza, ao analisar o emprego da metáfora da guerra a partir dessa época.

Constituíram-se paulatina e simultaneamente um problema, a violência, e um campo heterogêneo de medidas para contê-la e solucioná-la, com muitas propostas em experimentação. ${ }^{3}$

Interessam-nos particularmente, no entanto, as propostas de caráter pastoral, aquelas que visaram atacar a violência por meio da educação de caráter tutelar dos pobres urbanos, tidos como os seus maiores responsáveis. Sabemos que as tecnologias de guerra, ao se expandir, produziram ramificações associadas à ausência de formação moral dos pobres, que estaria na base de sua adesão, principalmente dos jovens, ao crime e à violência. O acompanhamento religioso no plano institucional secular expandiu-se ao longo dos anos e ganhou, em certos casos, grandes visibilidade e legitimidade.

O par religioso/secular em ações conjugadas veio a ser um poderoso instrumento no interior dos dispositivos de governo dos pobres. Com o objetivo de conter a criminalidade, de eliminá-la e de dominar os territórios em que supostamente ela se origina, forjaram-se modos de governar nos quais os usos correntes e cada vez mais expandidos da noção de crime tornaram mais complexa as relações entre esses domínios efetivamente entrelaçados. Surgiram novos atores, novas temáticas e novos modos de agir de religiosos e leigos nas igrejas, nas ruas e praças, na mídia, ocupando espaços públicos, impensáveis até pouco tempo atrás.

Nesse processo, ganhou importância específica o encontro entre uma vertente pentecostal de redenção dos pobres e uma perspectiva secular, hoje hegemônica, de salvação e, também, principalmente, de sua criminalização como inimigos da sociedade. Lembremos que há nesses encontros uma construção significativa de diferenciais de gênero e de raça em suas configurações tanto seculares quanto religiosas. Disso decorre o fato de que a guerra e a violência não parecem ser enfrentadas pelas mulheres de maneira igual às que são equacionadas pelos atores masculinos. Isso posto, abordaremos também a agência religiosa e secular das mulheres pelo que parece distingui-las quando vistas em relação com a guerra, isto é, outra relação com o sofrimento e com a dor.

\section{CAPTURAS}

Queremos agora, em continuidade com a etnografia de Cortes (20I4) a respeito dos empreendedores da fé, como o irmão Amorim, trazer à cena um campo mais 
difuso de discursos que tomam como ponto de partida a fala das vítimas e que discorrem sobre o sofrimento como desumano. Há uma diferença em termos de visibilidade, destaca Carly Machado (2016: 2)

Enquanto a violência é exibida ostensivamente através de diferentes meios, o sofrimento busca visibilidade a duras penas, confrontando-se continuamente com a invisibilidade produzida pelo silêncio da dor e o silenciamento da injustiça.

Grande parte das narrativas evangélicas que examinamos sobre o sofrimento dissocia-se, de forma ambígua e ambivalente, grosso modo, do veio dominante acusatório que criminaliza os pobres, responsabilizando-os sobre a violência que recai sobre eles próprios. A lógica da guerra, ao prevalecer, não dá lugar para aqueles que a sofrem, a não ser quando, em um encontro religioso, terão oportunidade de ser liberados dos demônios que os aprisionaram até então como bandidos violentos. A ambiguidade reside em parte na postulação da agência dos demônios como aqueles que destroem as pessoas e suas vidas e retiram dessas a sua dimensão humana, levando-os ao mau combate. Essa agência demoníaca, no entanto, como já argumentou Cecília Mariz (I999), em relação à Batalha Espiritual, ${ }^{4}$ não retira do indivíduo sua capacidade de reagir. Ele seria, em um primeiro momento, alguém que se deixou dominar e por isso sofre as consequências sociais e morais de suas escolhas: virou o alvo legítimo de uma política de extermínio, sofre com a pobreza e a desconsideração por sua pessoa (já que por meio da agência do demônio perdeu sua humanidade). Em um segundo momento, esse indivíduo é apresentado como alguém que se beneficiou de um encontro religioso. Encontro que transforma a invisibilidade de seu sofrimento em um martírio cristão, abrindo-lhe, conforme o prometido, o acesso à cidade. O sofrimento vivido como um martírio redentor passa a integrar os testemunhos dos "ex-bandidos" e "ex-traficantes" que trazem em seus corpos as marcas das violências pelas quais passaram.

Fala-se a respeito da morte, da tortura, da prisão como práticas que provocam efeitos de devastação sobre as pessoas. São narrativas que insistem na dor física e moral de suas vítimas, equacionando-as ao sofrimento, tal como esse foi grosso modo elaborado pelo cristianismo. O sofrimento é eliminado junto com as faltas morais do novo cristão. Somente suas marcas são exibidas e destacadas como um sinal de pertencimento a um mundo cruel que constitui os resgatados da morte também como homens.

Birman e Machado (20I2) abordaram uma variante dos "ex-bandidos" e "ex-tudo" discutidos por Mariana Cortes. Reivindicando a mesma identidade evangélica, os "ex-bandidos" são personagens de grande importância na construção de trajetórias ideais dos fiéis e da Igreja Assembleia de Deus dos Últimos Dias (Adud) em suas relações com certas instituições seculares.

$\mathrm{Na}$ igreja conduzida pelo pastor Marcos Pereira vemos como ele dotou de centralidade no culto os personagens "ex-bandidos", fazendo-os circularem 
entre lugares do crime e da punição para finalmente alcançarem outros portos por intermédio da Igreja. O termo pelo qual foram identificados na Adud é particularmente revelador:

Um dos principais objetivos missionários da ADUD é transformar os indivíduos, designados como resgatados da morte, em uma categoria especial de fiéis, que protagonizam nos vídeos suas próprias histórias de vida, arranjadas evidentemente por critérios e da perspectiva da igreja. As histórias testemunham suas experiências com a morte, com o sofrimento e com os territórios onde estiveram reclusos: esconderijos do tráfico, celas de delegacias e penitenciárias. Através de seus corpos marcados e transformados pelo sofrimento, os ex-bandidos e ex-traficantes operam como mediadores sociais para a formação de uma nova comunidade de salvação, em oposição à vida que deixaram para trás (Birman \& Machado, 20I2: 4).

A redenção propiciada pelos cultos por meio de imagens (vídeos e fotos) propagadas pela Adud é indissociável de uma salvação social e moral, designada por seu pastor como cidadania, e cujo horizonte maior seria a efetivação de uma limpeza territorial e moral da cidade pela conversão ilimitada e abrangente de seus habitantes. A relação entre a redenção dos resgatados da morte e a cidade ganha todo o seu sentido quando se percebe que os ditos resgatados teriam sido, de maneira naturalizada, identificados e tratados como inimigos da cidade. Assim, resgatá-los da morte é também resgatar a cidade dos criminosos que promovem seu cerco e que, nos embates armados nas periferias, seriam aqueles que mais morrem. Afirma-se, assim, um duplo resgate cujo objetivo é transformar esses indivíduos em cidadãos cristãos. Carly Machado muito justamente chamou atenção para esse entrelaçamento institucional de projetos de finalidade secular e de implementação religiosa como pastorais, no sentido foucaultiano do termo. ${ }^{5}$

A igreja do pastor Marcos compartilha com os fiéis um mapa virtual da criminalidade: os lugares do crime são identificados como aqueles que provocam a morte, onde se exerce a crueldade e se pratica a punição: lugares de onde Deus se ausentou. Os vídeos falam através de cenas, muitas delas violentas, sobre um trabalho religioso que é capaz de dobrar diante da ordem divina aqueles que estariam perdidos no mundo dos homens. As imagens de exorcismo reverberam o ato de dominar o demônio, a besta-fera, até ela ser dobrada pelo poder da força superior que física e espiritualmente se manifesta. Certos vídeos assistidos na igreja, também disponíveis em outras plataformas midiáticas, exibem os efeitos da crueldade praticados por traficantes que submetem bandidos rivais em seu poder. A câmera foca os corpos machucados, amarrados, vendados, com marcas das torturas que lhes foram infligidas. A intervenção do pastor permite salvá-los da submissão à morte, ao inferno e aos demônios do crime e da pobreza. E há ainda aqueles vídeos cujas cenas de exorcismo levam o público da igreja a compartilhar entre si e com os "ex-bandidos" presentes 
as capturas ritualizadas pelas quais estes últimos foram finalmente resgatados da morte. O didatismo dos vídeos visa reiterar o vínculo entre espaços seculares aparentemente inócuos como as prisões, perigosos como as favelas e pecadores como os bailes, com os efeitos positivos do trabalho missionário nessas periferias da cidade, onde tudo isso se acumula.

O humano do ponto de vista das atividades do pastor, como facilmente se deduz, é uma qualidade reconhecida no condicional: só se obtém pela conversão ao cristianismo. O testemunho recolhido por Mariana Cortes descreve a vida desprovida de qualidades humanas e, por isso, uma vida de sofrimento, de animalidade e também de aprisionamento. O valor mercantil dos "ex-tudo" se deve a sua elaboração como potentes instrumentos de conversão que podem ser produzidos e comercializados pela própria Igreja, como acontece na Adud, ou, como vimos, ser elaborados por esses pequenos empreendedores religiosos e vendidos em circuitos heterogêneos do mercado informal. Os relatos sobre crimes e várias formas de crueldade, como a tortura, o assassinato, o aprisionamento, o abandono e a miséria, são permanentemente explorados pela mídia secular e religiosa como a matéria-prima dessas formulações teológicas.

Com efeito, as narrativas cristãs e seculares tomam a mesma população como alvo de intervenções diversificadas e nem sempre com os mesmos objetivos explícitos. Trata-se de um campo em que as diferenças que até agora apontamos são também grandemente associadas a práticas interseccionais (Brah, 2006; Piscitelli, 2008) (que implicam distintamente religião, classe, raça e gênero) e são submetidas a articulações específicas e reiteradas diferencialmente por igrejas e instituições seculares. ${ }^{6}$ Personagens "resgatados da morte", na terminologia da Adud, são, como sabido, pobres, negros e homens moradores das periferias. É nos seus corpos que se materializa o potencial disruptivo desses sujeitos da morte e da violência. No entanto, há uma positividade atribuída a esse passado de crueldade na vida dos "ex-bandidos": é por meio da transformação benéfica do sofrimento em martírio que pode nascer mais um cristão na cidade.

Ao se ficcionalizar, como vemos, os eternos combates entre o Bem e o Mal, também se promove a guerra urbana intermitente e se justifica o valor pragmático da violência. A questão é saber, ao menos momentaneamente, de que "lado" o "ex-bandido" se encontra. Como "ex-bandidos" alguns conseguiram atribuir positividade plena a suas carreiras pregressas no crime e assim ampliar seu horizonte no presente. Carreiras de artistas gospel, de missionários, de pastores ou ainda de políticos se inscrevem em seus horizontes do possível. O mercado das terapias religiosas, do confinamento de menores e de drogados, aqueles da mídia, e também as ofertas crescentes em empregos como seguranças - cujas empresas e milícias organizadas apreciam homens fortes e seus vínculos com a polícia - não param de se desenvolver. As franjas e fronteiras porosas entre bandidos, policiais, funcionários e convertidos estão em cons- 
tante movimento. Percebem-se, como já se observou, o caráter circular das trajetórias de seus integrantes e a cristalização de certos circuitos entre a rua, a periferia e as instituições de acolhimento, de conversão e de punição. Nada disso parece apagar uma certa indefinição identitária.?

\section{SOFRIMENTO EM AÇÃO: PERFORMANCES DE GÊNERO EM ENCONTROS COM O ESTADO EM SUAS FACES MORAIS E RELIGIOSAS}

No entanto, as identidades, mesmo quando atribuídas a priori, não são fixas. E o sofrimento tampouco é uma categoria estável, como também observaram Talal Asad (2003, 20II) e sobretudo Veena Das (2015, 20IIa).

Perspectivas críticas em uma produção acadêmica recente têm permitido entender os jogos de poder e as relações conflitivas que transitam entre o legal, o ilegal e o criminoso, desfazendo o jogo binário e essencialista que dispõe em confrontos sem mediações os onipresentes policiais e bandidos ( $\mathrm{Ma}$ chado da Silva, 2008; Leite, 20I3; Telles, 20I0, 20I5; Hirata, 2010; Feltran, 2012; Efrem, 2017 e Rizek, 20II). O descentramento que assim se fez em relação a essas figuras altamente estereotipadas e mediatizadas tornou possível analisar práticas violentas no interior de dinâmicas sociais que estão longe de ser somente subsumidas a uma lógica criminal. Emergiu então um campo analítico de micropolíticas no qual essas categorias são analisadas em seus deslizamentos e assim apontam principalmente para a instabilidade desses processos, seus circuitos, atores e também a fluidez das identidades em jogo sob variadas circunstâncias (Fernandes, 20I3, 20I7; Rui, 20I4).

Ressaltemos agora um veio analítico nesse descentramento das figuras dos bandidos que se passa por meio das relações de gênero, as quais se corporificam mediante uma dimensão ética. Com efeito, os trânsitos entre o humano e o não humano são também trânsitos que se tornaram possíveis por forte mediação de caráter moral que passou a se exercer por meio de relações de gênero. É sobretudo o viés da maternidade posto em relevo que permite eventualmente a agentes do Estado reconsiderar os ditos bandidos como humanos. As figuras maternas em muitas ocasiões reposicionam seus filhos diante da lógica de extermínio a qual eles estão submetidos. Um campo de sentimentos derivados da moralidade materna por vezes ganha destaque e novas formas de agenciamento. De um depoimento de um policial militar que trabalhava em uma UPP na cidade do Rio de Janeiro, César Teixeira (20I5) destaca o caráter ambivalente de algumas narrativas policiais em relação ao ato de matar indivíduos. A única referência comum, acionada no momento dos homicídios, é o fato de suas vítimas serem homens, jovens, possivelmente negros e, principalmente, moradores de favelas. Um de seus entrevistados insiste sobre a atividade de matar bandidos como uma parte intrínseca de seu trabalho como policial militar. Revela um certo orgulho em contar que forjou muitas provas para assassinatos à queima-roupa em incursões que realizou em favelas. Os chamados 
"autos de resistência" no seu relato se transformam em "provas" de outra natureza: contabilizam via essa figura jurídico-policial um assassinato justificado como uma defesa legítima por parte do policial em serviço. Assim ele "conta" as mortes que provocou mediante essa referência compartilhada por policiais e familiares, vítimas de violência: trata-se bem de um homicídio designado por uma figura jurídica que todos sabem o que busca encobrir. No entanto, a relação de proximidade com certas mães levou-o a considerar em uma entrevista específica, destacada por Teixeira (2015: 87), esses mortos menosprezados como pessoas "falecidas":

Enquanto eu era polícia militar, um dos meus maiores orgulhos eram os autos de resistência, que é a morte de traficante em combate. Bato no peito: polícia. Tava de serviço. Subi e matei mesmo. Fui baleado em serviço. Eu tenho uma faixa de dez a I5 autos de resistência. Só que hoje, conheço Dona Vera, do apoio - trabalha comigo aqui -, [que] perdeu o filho em confronto com a polícia: Dona Margarida perdeu o filho em confronto com a polícia; a mãe do falecido Paulinho - teve aqui agora - a polícia matou o filho dela. A gente passa a ter contato com uma outra realidade.

Esse depoimento é revelador de uma figura emblemática, a mãe dos ditos bandidos, sobre a qual se reúnem movimentos que potencialmente desfazem a criminalização dos jovens moradores de favelas. Diante da fala das mães o policial militar, que contou com orgulho o número de autos de resistência que consta de sua folha de serviço, fez um movimento de pesar, seguido de referências que singularizam os jovens: "Dona Vera... trabalha comigo aqui... Dona Margarida..., a mãe do falecido Paulinho". Os jovens nessa entrevista foram percebidos por um efeito de mediação engendrado pela fala materna em um contexto de atendimento de jovens, o que alterou a forma do policial de os identificar.

Como se sabe, os dispositivos elaborados para tratar da violência articulam diferenças de raça, de classe e de gênero e assim facilitam, naturalizando, as acusações que designam os homens negros como propícios ao crime e às incivilidades, em contraste com as mulheres, posicionadas nesse jogo relacional como aquelas que melhor corporificam os valores morais. ${ }^{8}$ Os nexos com o ilícito e o ilegal, os trabalhos de ocasião, bem como o aprisionamento frequente, além da acusação de ligação com o tráfico são operados como signos de uma falha moral dos homens para responder como sujeitos cidadãos diante do Estado. A lógica da guerra, em suma, fortalece essa articulação essencialista dos gêneros pelo aprimoramento das tecnologias de governo relativas à violência.

Como se houvesse um consenso difuso e amplamente partilhado sobre a superioridade moral das mulheres em relação à violência e ao crime que abrange tanto pontos de vista religiosos como seculares. E de certa forma, o que relatamos aponta para os homens como o alvo dos trabalhos pastorais e para as mulheres como aquelas que teriam uma pouco questionada e (muito acionada) aderência aos valores morais seculares e cristãos. ${ }^{9}$ 
As articulações entre as práticas religiosas católicas, cristãs e também seculares indicam outro lugar concedido ao sofrimento quando se mencionam mulheres. Investido de uma agência específica, ele revela uma adesão apaixonada e visceral (Hirshkind, 20I7) à causa de seus filhos, o que contrasta com as formas de distanciamento e de indiferença cultivados por aqueles associados ao combate, tido como pragmático e necessário, aos inimigos da cidade. As acusações às mulheres feitas por policiais e juízes, em contextos de conflito, não as inscrevem facilmente em um campo cristalizado e relativamente estável "do lado" dos inimigos da sociedade. Como sinalizam Vianna e Farias (20I I), há tentativas recorrentes de inversão de papéis para, em julgamentos dos policiais militares acusados pelas mortes de seus filhos, os recolocar no banco dos réus. E assim a luta das mães inclui esforços para coibir a criminalização da vítima e delas próprias nos julgamentos. Adriana Vianna (20I5: 4I2), ao analisar a presença materna na construção das "vítimas" em julgamentos sobre jovens assassinados, observa como essas distinções são disputadas em seus sentidos por meio da figura materna:

No mesmo julgamento, ocorrido no final de 2010, pudemos ver o quanto a presença materna atua como elemento de ponderação moral na construção da "vítima", indicando a formação de uma curiosa figura didática mãe-filho como o ponto para o qual convergem as avaliações sobre a veracidade de se estar lidando efetivamente com a morte de um "trabalhador". A forma como precisa ser exaustivamente demonstrado que os mortos não tinham envolvimento com o tráfico, que estudavam ou trabalhavam não é feita sem menções constantes à mãe, do mesmo modo que ela não cansa de enunciar, seja nas manifestações, seja para outros participantes do julgamento, que havia "criado" direito o seu filho.

A perseverança, enfatiza Vianna (20I5: 4I2), é parte dessa relação materna reconhecida aliás até por seus possíveis acusadores como um argumento legítimo a respeito de seus filhos: "Como asseverou o assistente de acusação no mesmo julgamento, 'mãe de traficante não fica anos lutando por justiça'”.

Há mais de 25 anos surgiu uma nova figura no encontro de mulheres com o Estado. Como reação de um grupo de mães a chacinas e desaparecimentos de seus filhos, organizou-se o movimento de mães contra a violência no Rio de Janeiro (Birman \& Leite, 2004; Araujo, 20I I, 20I4; Farias, 20I5). Os esforços cotidianos das mães, figuras centrais envolvidas nesta causa, em percorrer os descaminhos da burocracia estatal, em ultrapassar a ilegibilidade de suas regras, em confrontar os desmandos e ameaças das forças policiais têm pavimentado seus movimentos que, desse modo, por meio de cotidianos de sofrimento afirmado e reivindicado, resistem à guerra sem fim.

Não é possível considerar com esses exemplos que o estatuto moral das mães foi acionado mediante conexões religiosas diretamente afirmadas. A religião, entretanto, se faz presente por muitos meios no cotidiano das mulheres 
(Garcia dos Santos, 20I4) e participa da elaboração dessas lutas. Preferimos sugerir que a pauta desses movimentos tem sido organizada com base em princípios identificados como seculares, como a luta por justiça a seus filhos, o que se pode deduzir das análises etnográficas de Adriana Vianna e Juliana Farias (20I I). No entanto, o secular nesse e em outros casos, encontra-se embebido em um pano de fundo religioso que o constituiu nos quadros de uma nação católica. Embora se saiba que são as mulheres que enchem os cultos das igrejas evangélicas e de todas as outras, são principalmente as modalidades de articulação entre as diferenças relativas ao gênero e à raça que nos ajudam a compreender as relações entre as mulheres e o sofrimento nos eventos que as mobilizam contra a guerra aos ditos inimigos da sociedade, seus filhos e parentes próximos.

A condição de vítima e de pessoa sacrificada está sem dúvida entrelaçada com certos imaginários católicos que relegam às mulheres, quase automaticamente, um sentido de sacrifício marcado pela passividade, emblemático das tradições marianas. A passividade acompanharia as mulheres que sofrem como figuras do martírio decorrentes dessa tradição que forjou também nessa relação entre sofrimento e santidade a narrativa católica hegemônica sobre a nação brasileira (cf. Steil, Mariz \& Reesnick, 2003). Como sugere Cecília Mariz (2003: 26I), nas manifestações do catolicismo popular haveria "a glorificação do martírio". Marjo Theije e Els Jacobs (2003: 37) reforçam a percepção do viés de gênero estruturando os cultos às aparições de Maria.

Percebe-se que o enquadramento nessa literatura das mulheres que defendem seus filhos por meio das imagens do sacrifício feminino não dá conta inteiramente das formas de agir dessas mulheres. Isso porque o ato de se sacrificar (e de sofrer) é aquele que parece prover de agência a figura materna. Como destaca Adriana Vianna (20I5), elas fazem do sofrimento um modo de intervenção específico, capaz de afrontar, com o desgaste físico e moral que também as alimenta, a luta cotidiana.

O sacrifício assim faz parte do que em alguns trabalhos se indica como o cotidiano das mulheres, que se espraia entre trabalho, casa e cuidados e não se distingue da vida tal como é posta e vivida (Das, 20I Ia, 20I5). É em um modo minoritário e quase invisível que textos etnográficos chamam atenção para o modo como as mulheres acionam a justiça, a polícia, o tráfico, o pastor, o pai/ mãe de santo buscando aliados e recursos para afrontar as forças em jogo em encontros diversos, nas igrejas, nas periferias, nos julgamentos, nas situações de confronto armado e em suas moradias.

Como vimos, o exorcismo se apresentou como um instrumento altamente mediatizado de ação religiosa para retirar os homens das situações de envolvimento com o crime e os redimir. O recurso a outros instrumentos religiosos, menos legítimos, mas nem por isso considerados ineficazes (Maggie, I 992), foi minuciosamente descrito por Camila Pierobon (2018) em sua tese de dou- 
torado. Leonor, sua interlocutora de pesquisa, contou-lhe detalhadamente como se dedicou intensamente a preparar um número gigantesco de trabalhos de macumba para salvar sua filha da prisão, onde ela foi barbaramente torturada. É interessante destacar que Leonor frequentava uma igreja evangélica cujo pastor recusou ajudá-la, por que sua filha estaria comprometida com o tráfico. Assim Leonor resolveu - diante da terrível situação que ela enfrentava como presa, torturada, e submetida a um julgamento claramente orientado para condená-la por associação com o tráfico - dedicar-se, em segredo, mas com afinco, a fazer trabalhos mágicos para inviabilizar, com o auxílio de suas entidades (Exu e Pombagira), sua condenação. Sua atividade religiosa nesse caso decorreu, como assinala Pierobon (20I8), fundamentalmente de uma ética de cuidados que a sustenta subjetivamente, dando-lhe condições de habitar o mundo sempre brigando, na luta, a favor de seus filhos e de sua mãe doente.

Se o entrelaçamento entre o religioso e o secular levou principalmente pastores, ao menos nos casos aqui tratados, a ganhar mais visibilidade na esfera pública e a promover suas igrejas como atores importantes no combate ao crime e à violência, o mesmo não aconteceu com as mulheres. A crueldade e a violência praticadas nessas guerras sem fim se reafirmam como masculinas, bem como as alianças entre certas igrejas e segmentos do Estado para exercer o pastorado de corpos e almas.

A mediação feminina, ainda que com limites evidentes, tem operado com frequência de forma mais claramente localizada, desfazendo vieses generalizantes que reiteram seus filhos e parentes como inimigos. Nas redes que integram homens, mulheres, filhos e parentes, o pastor pode abençoar um irmão que se afastou da igreja, pode acolher jovens desviados, envolvidos em atividades escusas. Do mesmo modo, é possível ao padre católico, e também ao pastor e ao pai de santo, bem como ao dirigente espírita, proteger algum antigo fiel em fuga. Essas ocorrências raras, por certo, também articulam religião e política, secularismo e violência, mas assim o fazem principalmente por meio da mediação física e moralmente encarnada pelas mulheres com o sofrimento, em contraste com os homens, marcados pela violência. Essas práticas, pouco visíveis, desfazem em algum nível as grandes rupturas que legitimam cotidianamente a guerra e o número crescente de indivíduos a eliminar ou, quem sabe, a salvar e redimir via os muitos programas de tutela, alimentados pelos governos dos pobres. Em suma, a intervenção feminina não se apresenta tão condicionada às fronteiras que separam os que têm direito à vida dos que podem morrer.

Terminemos então ressaltando que em meio aos efeitos dessas articulações entre práticas seculares e religiosas destaca-se o fato de se encontrarem constituídas também mediante uma ética de cuidados, como assinalou Pierobon (20I8). Uma ética que, essencialmente, não se pratica no condicional pelo respeito exigido às clivagens políticas e aos dispositivos da violência. Seus impe- 
rativos são de base relacional, possibilitando assim que os elos familiares prevaleçam sobre quaisquer outras considerações. Ao finalizar o texto com as mediações das mulheres queremos chamar atenção para esses seus movimentos que, por mais invisíveis que sejam, são compostos por gestos que confrontam e se contrapõem à guerra sem fim por meio de uma lógica relacional com base em uma ética de cuidados. A dissolução do eixo relativo à distinção entre o humano e o não humano parece se constituir como um movimento nos dias de hoje fortemente minoritário, no qual se destaca um viés de gênero também inscrito nos entrelaçamentos religiosos e seculares.

Recebido em I2/3/20I8 | Revisto em 9/I/20I9 | Aprovado em 4/2/2019

Patricia Birman é doutora em antropologia social pela Universidade Federal do Rio de Janeiro

(UFRJ). É professora titular de antropologia da Universidade do Estado do Rio de Janeiro (Uerj) e pesquisadora do CNPq. 


\section{NOTAS}

Cf. Carly Machado (20I4 e 20I6) analisou dois importantes projetos que associam a salvação individual à salvação da cidade, a saber, o projeto Afro-Reggae e o projeto do pastor Marcos Pereira, ambos dedicados a constituir um nexo entre estes dois objetivos, vistos, portanto, como interligados: salvar a cidade do crime e os criminosos da morte. Para uma análise do projeto do pastor Marcos Pereira, ver Birman \& Machado (20I2) que retomaremos aqui. É importante ressaltar que o religioso nesses artigos citados é compreendido por uma perspectiva relacional, sem sentido fixo e estabelecido, conforme a perspectiva inaugurada por Talal Asad (I993). Para análises nessa perspectiva no Brasil, consultar os trabalhos de Emerson Giumbelli (20I4).

2 Cf. nessa mesma perspectiva Achilles Mbembe (20I6: I33); ele descreve o que entende por colônia aproximando sua construção das formas atuais de exercício do governo: "Seus exércitos não formam uma entidade distinta, e suas guerras não são guerras entre exércitos regulares. Não implicam a mobilização de sujeitos soberanos (cidadãos) que se respeitam mutuamente, mesmo que inimigos. Não estabelecem distinção entre 'inimigo' e 'criminoso'. Assim, é impossível firmar a paz com eles. Em suma, as colônias são zonas em que a guerra e a desordem, figuras internas e externas da política, ficam lado a lado ou se alternam. Como tal, as colônias são o local por excelência em que os controles e as garantias de ordem judicial podem ser suspensos - a zona em que a violência do Estado de exceção supostamente opera a serviço da 'civilização'".

3 Não cabe neste artigo desenvolver tudo aquilo que ao longo dos anos foi apresentado pelos governantes como novas formas e tecnologias de gestão da violência. Novas armas, novos equipamentos de vigilância, novos agentes públicos para tratar do problema, novos segmentos do Estado envolvidos e criados: Força Nacional, Exército, serviços de inteligência, assessorias especiais etc. Não conheço trabalhos que se tenham dedicado a levantar esse campo e sua progressão. Podemos destacar aqueles fundamentais que ao longo da última década se voltaram para compreender sociologicamente "a produção das mar- 
gens" (Das, 2004) como um processo em curso na cidade (Leite, 2013; Machado, 2008, entre outros)

4 Cf. O trabalho de Raquel Sant'Ana (2017) sobre as premissas da Batalha Espiritual e da Teologia do Domínio, ambas pentecostais. Enquanto a Batalha Espiritual é agenciada para o combate aos demônios, identificando-os mediante comportamentos permissivos e discursos favoráveis à pauta do aborto e do homossexualismo, a Teologia do Domínio é descrita como uma forma de agenciamento direcionada para um objetivo político e religioso, a saber, conquistar os espaços sociais e políticos, "ocupá-los" política e religiosamente.

5 Aponta como parte de uma biopolítica as tentativas de controlar e disciplinar institucionalmente esses indivíduos que tanto são postos em prisões quanto circulam em instituições religiosas e terapêuticas.

6 O trabalho de Avtar Brah (2006) e de Adriana Piscitelli (2008) nos inspiraram particularmente. Mediante a análise das práticas interseccionais, insistem sobre "as articulações entre diferenças". Distanciam-se, assim, de uma perspectiva essencialista e a-histórica relativa aos estudos de gênero e raça.

7 Adriana Fernandes (2013, 20I7) analisa certos circuitos de populações de rua que envolvem diferentes modalidades de busca por moradia que podem incluir abrigos, centros de acolhimento religiosos, prisões e hospitais etc. Os circuitos do crack foram analisados por Taniele Rui (20I4) nesse mesmo sentido, destacando as idas e vindas entre a rua e os recolhimentos compulsórios. Recentemente no Rio de Janeiro se aprovou uma lei que permite a presença de policiais militares no interior de estabelecimentos escolares, para coibir ataques criminosos e violentos de estudantes e também de pessoas estranhas aos membros do staff escolar. Essa lei que militariza as instituições escolares também cria uma abertura para incluir os estudantes em circuitos de punição: da escola para a delegacia, desta para um centro de acolhimento de menores etc.

8 O programa Bolsa Família, por exemplo, aciona o que seriam faltas morais masculinas - como a bebida, o gasto perdulário do salário - para direcionar o recebimento da bolsa pelas mulheres. 
9 Em um certo momento, as mulheres foram chamadas a participar de projetos de pacificação da cidade como protagonistas nas favelas. Sua atribuição era auxiliar no trabalho de controle da juventude local, à base de conselhos fornecidos aos que conseguiam identificar como sujeitos às atrações do tráfico. Jovens em situação de risco, como foram volta e meia designados ao longo dos últimos 30 anos, eram seus alvos. Esse dispositivo, ao menos teoricamente, dotou as mulheres de um papel de tutela. O programa inaugurado pelo antigo ministro Tarso Genro, do governo Lula, queria inovar o tratamento da segurança pública por meio de uma política de aproximação com os jovens negros favelados que teria as mulheres também faveladas como suas auxiliares. Mulheres da Paz surgiu nos anos 2000 (cf. Sorj, 20I6).

\section{REFERÊNCIAS BIBLIOGRÁFICAS}

Agamben, Giorgio. (2004). Estado de exceção. São Paulo: Boitempo.

Araújo, Fábio. (20I4). Das técnicas de fazer desaparecer corpos. Rio de Janeiro: Lamparina/Faperj.

Araújo, Fábio. (20II). Narrativas do terror e do sofrimento. Relato materno sobre o desaparecimento forçado do filho. Sociedade e Cultura, I4/2, p. 333-344.

Asad, Talal. (20II). Reflexões sobre a crueldade e a tortura. Revista Pensata, I/I, p. I60-I63.

Asad, Talal. (2003). Formations of the Secular: Christianity, Islam, Modernity. Stanford: Stanford University Press.

Asad, Talal. (1993). Genealogies of religion. Discipline and reasons of power in Christianity and Islam. Baltimore: The John Hopkins University Press.

Birman, Patrícia. (2017). Governing the poor: secular and religious practices in debate. In: Mapril, José; Blanes, Rui; Giumbelli, Emerson \& Wilson, Erin (orgs.). Secularisms in a postsecular age? Palgrave: Macmillan.

Birman, Patrícia. (20I5). Ocupações: territórios em disputa, gêneros e a construção de espaços comuns. In: Birman, Patrícia; Leite, Márcia; Machado, Carly \& Carneiro, Sandra 
Sá (orgs.). Dispositivos urbanos e trama dos viventes: ordens e resistências. Rio de Janeiro: FGV.

Birman, Patrícia \& Leite, Márcia (orgs.). (2004). Um mural para a dor: movimentos cívicos religiosos por justiça e paz. Porto Alegre: UFRGS.

Birman, Patrícia \& Machado, Carly. (2012). A violência dos justos: evangélicos, mídia e periferias da metrópole. Revista Brasileira de Ciências Sociais, 27/80, p. 55-69.

Brah, Avtar. (2006). Diferença, diversidade, diferenciação. Cadernos Pagu, 26, p. 329-376.

Comaroff, Jean \& Comaroff, John. (20I2). Theory from the South or How Euro-America is evolving toward Africa. Boulder: Paradigm Publishers.

Cortes, Mariana. (20I4). O mercado pentecostal de pregações e testemunhos: formas de gestão do sofrimento. Religião e Sociedade, Rio de Janeiro, 34/2, p. I84-209.

Das, Veena. (2015). Affliction. Health, disease and poverty. New York: Fordham University Press.

Das, Veena. (2011a). Life and words: violence and the descent into the ordinary. Berkeley: University of California Press.

Das, Veena. (20IIb). O ato de testemunhar: violência, gênero e subjetividade. Cadernos Pagu, 37, p. 9-4I.

Das, Veena \& Poole, Deborah. (2004) Anthropology in the Margins of the State. Santa Fé: School of American Research Press.

Efrem Filho, Roberto. (2017). Os meninos de Rosa: sobre vítimas e algozes, crime e violência. Cadernos Pagu, 5I, p. I75-106.

Farias, Juliana. (2015). Da capa de revista ao laudo cadavérico; pesquisando casos de violência policial em favelas cariocas. In. Birman, Patrícia; Leite, Márcia; Machado, Carly; Carneiro, Sandra de Sá (orgs.). Dispositivos urbanos e tramas dos viventes: ordens e resistências. Rio de Janeiro: FGV/Faperj, p. 4I9-450.

Feltran, Gabriel. (2012). Governo que produz crime, crime que produz governo: o dispositivo de gestão do homicídio em São Paulo (I992-20II). Revista Brasileira de Segurança Pública. São Paulo, 6/2, p. 232-255. 
Fernandes, Adriana. (2017). Medicalização e quedas: formas de narrar a contrapelo. Apresentação no Seminário Fazendo mover, fazendo parar: entre prisões, abrigos, ruas, pessoas e documentos. Museu Nacional, UFRJ (mimeo).

Fernandes, Adriana. (2013). Escuta ocupação: arte do contornamento, viração e precariedade no Rio de Janeiro. Tese de Doutorado. PPCIS/Universidade do Estado do Rio de Janeiro.

Garcia dos Santos, Yumi. (20I4). Família, trabalho e religião das mulheres assistidas em São Paulo. Cadernos de Pesquisa, 44/I52, p. 400-42I.

Giumbelli, Emerson. (20I4). Símbolos religiosos em controvérsias. São Paulo: Terceiro Nome.

Graham, Stephen. (2016). Cidades sitiadas. O novo urbanismo militar. São Paulo: Boitempo.

Hirata, Daniel. (2010). Sobreviver na adversidade: entre o mercado e a vida. Tese de Doutorado. PPGS/Universidade de São Paulo.

Hirschkind, Charles. (2017). Existe um corpo secular? Religião e Sociedade, 37/I, p. I75-I89.

Leite, Márcia Pereira. (2013). La favela et la ville: de la production des "marges" à Rio de Janeiro. Brésil, 3, p. Io9-I28. Leite, Márcia Pereira. (2000). Entre o individualismo e a solidariedade: dilemas da cidadania e da política no Brasil. Revista Brasileira de Ciências Sociais, I5/44, p. 73-90.

Machado, Carly. (20I4). Pentecostalismo e o sofrimento do (ex-)bandido: testemunhos, mediações, modos de subjetivação e projetos de cidadania nas periferias. Horizontes Antropológicos, Porto Alegre, 20/42, p. I53-I80.

Machado, Carly. (20I3). É muita mistura: projetos religiosos, políticos, sociais, midiáticos, de saúde e segurança pública nas periferias do Rio de Janeiro. Religião e Sociedade, $33 / 2$, p. I3-36.

Mbembe, Achilles. Necropolítica. (2016). Arte \& Ensaios, Rio de Janeiro, 32, p. I22-I5I.

Machado da Silva, Luiz Antonio (org.). (2008). Vida sob cerco: violência e rotina nas favelas do Rio de Janeiro. Rio de Janeiro: Nova Fronteira/Faperj. 
Maggie, Yvonne. (I992). Medo do feitiço: relações entre magia e poder no Brasil. Rio de Janeiro: Arquivo Nacional.

Mariz, Cecília. (2003). Rainha dos Anjos. A aparição de Nossa Senhora em Itaipu, Niterói. In: Steil, Carlos Alberto; Mariz, Cecília \& Reesink, Misia (orgs.). Maria entre os vivos. Reflexões teóricas e etnografias sobre aparições marianas no Brasil. Porto Alegre: UFRGS, p. 269-282.

Mariz, Cecília. (I999). A teologia da guerra espiritual: uma revisão da literatura socioantropológica. Revista Brasileira de Informação Bibliográfica em Ciências Sociais, 47, p. 33-48. Pierobon, Camila. (2018). Tempos que duram e lutas que não acabam: o cotidiano de Leonor e sua ética de combate. Tese de Doutorado. PPCIS/Universidade do Estado do Rio de Janeiro.

Piscitelli, Adriana. (2008). Interseccionalidades, categorias de articulação e experiências de migrantes brasileiros. Sociedade e Cultura, II/2, p. 263-274.

Rizek, Cibele \& Georges, Isabel. (2016). Práticas e dispositivos: escalas, territórios e atores. Contemporânea, 6/I, p. 5I-73.

Rui, Taniele. (20I4). Nas tramas do crack - etnografia da abjeção. São Paulo: Editora Terceiro Nome.

Sant'Ana, Raquel. (20I7). A nação cujo Deus é o Senhor: a imaginação de uma "coletividade evangélica" a partir da Marcha para Jesus. Tese de Doutorado. PPGAS/Universidade Federal do Rio de Janeiro.

Sorj, Bila. (20ı6). Políticas sociais, participação comunitária e a desprofissionalização do care. Cadernos Pagu, 46, p. 107-I 28.

Steil, Carlos Alberto; Mariz, Cecília \& Reesink, Misia (orgs.). Maria entre os vivos. Reflexões teóricas e etnografias sobre aparições marianas no Brasil. Porto Alegre: UFRGS.

Teixeira, Cesar Pinheiro. (20I5). O 'policial social': algumas observações sobre o engajamento de policiais militares em projetos sociais no contexto de favelas ocupadas por UPPs. Dilemas, 8/ı, p. 77-96.

Telles, Vera. (20I5). Cidade: produção de espaços, formas de controle e conflitos. Revista de Ciências Sociais. Fortaleza, 46/I, p. I5-4I. 
Telles, Vera. (2010). A cidade nas fronteiras do legal e ilegal. Belo Horizonte: Argumentum.

Theije, Marjo \& Jacobs, Els. (2003). Gênero e aparições marianas no Brasil contemporâneo. In: Steil, Carlos Alberto; Mariz, Cecília \& Reesink, Mizia (orgs.). Maria entre os vivos. Reflexões teóricas e etnográfias sobre aparições marianas no Brasil. Porto Alegre: Ed. UFRGS.

Vianna, Adriana. (20I5). Tempos, dores e corpos. Considerações sobre a "espera" entre familiares de vítimas de violência policial no Rio de Janeiro. In: Birman, Patrícia; Leite, Márcia Pereira; Machado, Carly \& Carneiro, Sandra de Sá (orgs.). Dispositivos urbanos e tramas dos viventes, ordens e resistências. Rio de Janeiro: FGV/Faperj, p. 405-4I8. Vianna, Adriana \& Farias, Juliana. (20II). A guerra das mães: dor e política em situações de violência institucional. Cadernos Pagu, 37, p. 79-II6. 


\section{NARRATIVAS SECULARES E RELIGIOSAS SOBRE A VIOLÊNCIA: AS FRONTEIRAS DO HUMANO NO GOVERNO DOS POBRES}

\section{Resumo}

Analisaremos encontros e confrontos na esfera pública em discursos religiosos e seculares sobre a violência. Sugerimos que o tratamento da violência nesses discursos possui como eixo a distinção entre o humano e o não humano, bem como as pequenas nuanças dispostas ocasionalmente em suas fronteiras. Essas se configuram de forma instável e variada tanto em suas versões seculares quanto religiosas, incluindo também os sentidos atribuídos à dor e ao sofrimento. As ideias religiosas de dor e de sacrifício como caminhos de redenção já conduziram tanto à recusa quanto a um consentimento implícito das práticas da tortura, do homicídio, do crime e da violência. O repertório de problematizações e de intervenções micropolíticas em torno da violência nos encaminhou para a importância das relações de gênero nesse campo, com destaque para as éticas que hoje estruturam certas condutas, tanto religiosas quanto seculares.

\section{SECULAR AND RELIGIOUS NARRATIVES ON VIOLENCE: THE BOUNDARY OF THE HUMAN IN THE GOVERNANCE \\ OF THE POOR}

Abstract

The article analyses the encounters and confrontations in the public sphere in religious and secular discourses on violence. I suggest that the treatment of violence in these discourses pivots on the distinction between the human and the non-human, as well as the small nuances located occasionally on their boundaries. These are configured in unstable and varied forms in both their secular and religious versions, including too the meanings attributed to pain and suffering. The religious ideas of pain and sacrifice as paths to redemption already lead to both a rejection of and an implicit consent to the practices of torture, homicide, crime and violence. The repertoire of problematizations and micropolitical interventions surrounding violence points to the importance of gender relations in this field, highlighting the ethics that today structure certain conducts, religious and secular alike.
Palavras-chave

Secularismo;

violência;

sofrimento;

religião;

gênero.

Keywords

Secularism;

violence;

suffering;

religion;

gender. 